\title{
Structural investigations and modelling of the Bell Tower of Santa Maria del Carmine
}

\author{
F. Ceroni ${ }^{1}$, M. Pecce ${ }^{1}$, F. Palmaccio ${ }^{2}$ \& G. Manfredi ${ }^{2}$ \\ ${ }^{I}$ Department of Engineering, University of Sannio, Benevento, Italy \\ ${ }^{2}$ Department of Structural Analysis and Design, University of Naples \\ Federico II, Napoli, Italy
}

\begin{abstract}
Detailed historical and architectonical investigations (geometrical and material surveys, destructive and non-destructive tests) have been performed on the Bell Tower of Santa Maria del Carmine sited in Naples as preliminary inquiries into the structural analysis. An experimental dynamic characterization of the Tower was also realized considering environmental source vibrations. Linear analysis for static loads, linear modal analysis and nonlinear dynamic analysis (Push Over) have been developed by a 3D model in order to assess the safety condition of the structure. A study of local out-of-plane failure mechanisms has also been performed.

Keywords: historical masonry buildings, in situ inquiries, FEM analysis, Push Over.
\end{abstract}

\section{Introduction}

The evaluation of state and the design of a restoration project for an historical building needs technical investigations involving various types of competences. Historical, archival and bibliographical documentations are useful for an historical-critic survey necessary to characterize, analyze and record the origin of the structure and the vicissitudes during its history, its characteristic elements, the anomalous ones, the structural morphology and its static conditions. For an historical masonry building the variability of parameters as wall texture, connections, nature and dimensions of its component elements (i.e. disposition and dimension of blocks), coupling and mechanical properties of the various constituent materials (masonry blocks, bricks, mortar) could make each structure 
a singular case, so that detailed in situ experimental analysis are requested (Binda et al. [1]). Furthermore the original mechanical properties of the materials, already variable depending on the geological history of the stones, are often modified by aging and environmental effects.

Modifies in the architectonical or structural geometrical assessment of the examined building and of the surrounding ones can influence restrain conditions, presence of pushing actions, contribute to mass participation for seismic actions, so that both the local and global structural behaviour can be prejudiced.

Investigations to assess the structural behaviour of an historical masonry building, to develop a theoretical model and to design eventually interventions may be divided in different categories (historical, architectural, structural). A correct assessment of the structural behaviour appears to be tightly associated with the utilization of non destructive tests (Binda et al. [1]; Carpinteri and Bocca [2]). At the same time, the data acquired with these techniques can be efficiently completed and well interpreted by an historical survey and an architectural analysis of the construction, to the aim of integrating information of different categories of investigations.

In this paper a detailed analysis of the Bell Tower of Santa Maria del Carmine in Naples is reported as 'case study' of a generalized methodology to approach the study of an historical building starting from the preliminary inquires until the design of solutions to improve the safety of the structure.

\section{Description and in situ inquires of the Bell Tower}

\subsection{History and description of structure}

The monumental complex of Carmine (Figure 1) is located at the extreme periphery of the ancient city of Naples. The actual seventeen century structure rises out of the XIV century basement of the original Tower. During an earthquake in the 1456 the upper portion of the building fell down, making necessary to demolish the remaining part with exception of the basement. In 1458 the construction of a new Bell Tower was initiated, but only in the 1615 the construction was resumed and finished within 1631. The Tower is $68 \mathrm{~m}$ high and made by six levels plus the ground level (Figure 1): the first two levels are surrounded by other buildings (church, congregation building, cloister), while the upper ones are free on each side.

Historical investigations have revealed that the Bell Tower and the adjacent church were originally separated and the current assessment is due to successive modifications of the church facade, originally placed behind the front side of the Tower, and to the refilling of the gap between the two structures. The Congregation building (on the right side of the Tower in Figure 1) was built after the Tower without any structural connection. The Tower is made by faced masonry of yellow Neapolitan tuff up to $41.4 \mathrm{~m}$ level with a rectangular plant (Figure 2(a)). External covering in piperno and internal covering in peperino stones are present for the first $7.5 \mathrm{~m}$ of the basement. Tuff is a volcanic natural stone typical of the area nearby Naples with a characteristic yellow colour 
extensively used as construction material in Southern Italy due to its good mechanical properties in compression associated with a significant lightness. Piperno and peperino are volcanic lapideous dark stone generally used as covering with architectonical functions. From level $41.4 \mathrm{~m}$ up, plants become octagonal (Figure 2(b)) and the walls are made by clay bricks for the all thickness, even if at some levels original symmetrical openings have been closed with tuff curtains covered by a layer of clay bricks. The mortar joints and the filling material between the faced tuff walls are of pozzolanic nature.

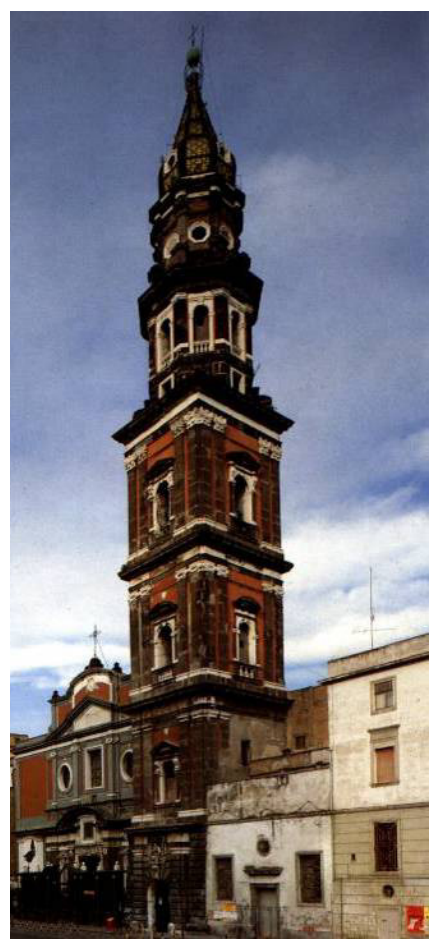

(a)

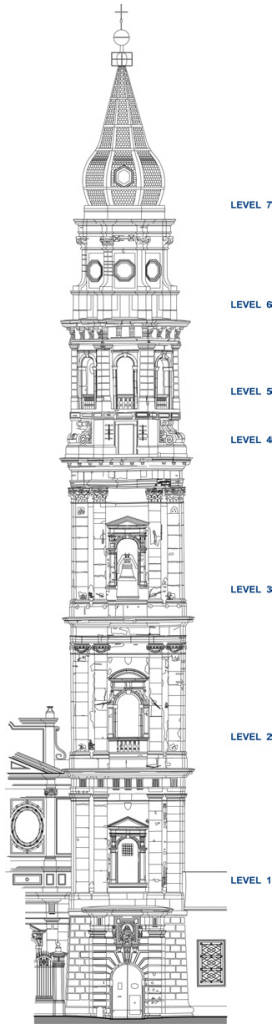

(b)

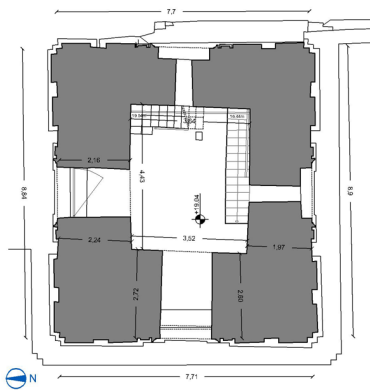

(a)

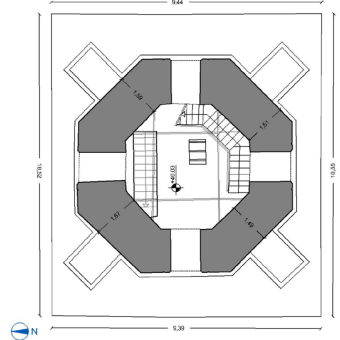

(b)

Figure 1: $\quad$ (a) and (b) front prospect of the Tower of Santa Maria of Carmine.

Figure 2: $\quad$ Plan view

(a) $19.0 \mathrm{~m}$;

(b) $41.4 \mathrm{~m}$.

Various interventions, not always documented, altered the original configuration of the Tower. The old vaults ceiling were partially removed and modified introducing RC slabs. From the 1st to the 7th level, sometimes passing through the vaults, an RC stair realized in the 1950s is connected to the masonry walls also by inclined mortar injections reinforced by steel bars. Chains made by steel bars with external anchorage plate are dated in the XIX century, while some internal chains, passing through RC stairs, were probably placed in the 
1920s-1930s before realization of the stairs. Other internal steel chains and steel reinforced mortar injections were realized in the 1970 s to remedy to damages caused by seismic actions and to improve the connections between the orthogonal walls. A lot of chains present a diffuse superficial corrosion or local damage and probably are not all effective. After the earthquake of 1980, additional steel reinforced mortar injections were realized in the wall corners.

\subsection{Mechanical characterization of materials}

Basing on preliminary surveys a detailed program of experimental tests in situ has been projected and realized (Ceroni et al. [3]) to characterize geometrical, mechanical and structural aspects synthesized in this paper for the results useful to the modelling of the Tower. In particular eight single flat-jack tests were realized at four levels $(0,8.7,19,40 \mathrm{~m})$ on opposite walls to evidence presence of asymmetry in stress distribution. Levels were chosen basing on variations of wall materials and plant geometry. The results evidenced a substantial uniformity of the stress distribution with a progressive reduction along the height. Three double flat-jack tests were also realized in correspondence of the single flat-jacks to evaluate the compressive strength, the constitutive relationship and the elastic modulus of the investigated masonry. By these tests, the mean compressive strength of masonry resulted about $1.45 \mathrm{MPa}$ for tuff and $2.40 \mathrm{MPa}$ for clay bricks, while the maximum stresses, registered at the basis of the Tower, are however contained under the $25 \%$ of the compressive strength, showing that for the permanent vertical loads the Tower appears to be in good condition.

Basing on the samples extracted at different points, mean values of density of tuff stone and clay bricks were estimated as $15 \mathrm{kN} / \mathrm{m}^{3}$ and $17 \mathrm{kN} / \mathrm{m}^{3}$. The mean compressive strength of cylindrical tuff samples was evaluated about 2.6MPa. Since the in situ tests were realized on masonry, the results the properties are referred to the assembled systems taking into account thickness of mortar, dimension and disposition of blocks, connections between the two faces of the wall, typology of filling materials between faces, so that all the mechanical properties result lower than the stone ones. The values of elastic modulus have been defined by correlating the results of double flat jacks with the ones obtained by sonic tests (Ceroni et al. [3]). The mean values of elastic modulus, considering all the measures, result about $530 \mathrm{MPa}$ and $850 \mathrm{MPa}$ for tuff and clay bricks. Heterogeneity of filling materials in faced masonry give scattered measures.

The strain levels of twenty-two steel chains were monitored by vibration sources technique evidencing that most of them bear tensile stresses variable between 27 and $99 \mathrm{MPa}$ and that 8 chains, subjected to relevant corrosion phenomena, are unloaded.

\subsection{Dynamic characterization}

A dynamic characterization of the structure has been performed considering environmental source vibrations as traffic, wind and bell for three days. Extra vibrations were produced by localized impulses using an instrumented hammer. 
Several mono-axial accelerometer sensors have been positioned at different heights (levels 2-7, Figure 1(b)) according to various measurement schemes. Sensors were fixed in the corner of the floor to check eventual asymmetric behaviours of these nodes.

Results evidenced that the first four modal shapes are flexural and the fifth is torsional. The $1^{\text {st }}$ and the $3^{\text {rd }}$ modal shapes are related to the $\mathrm{X}$ axis (direction Church-Congregation), while the $2^{\text {nd }}$ and $4^{\text {th }}$ modal shapes are related to the $\mathrm{Y}$ axis: the modal shapes along the two directions are uncoupled and have similar values of frequencies.

In Figure 3 the first four modal shapes of the Tower in terms of acceleration normalized respect to the maximum one relieved at the highest monitored level of the Tower $\left(7^{\text {th }}\right.$ level at $\left.57 \mathrm{~m}\right)$ are depicted. For each direction, the $1^{\text {st }}$ and $2^{\text {nd }}$ modal shapes show a cantilever feature, while for the $3^{\text {rd }}$ and $4^{\text {th }}$ ones there is a curvature inversion.

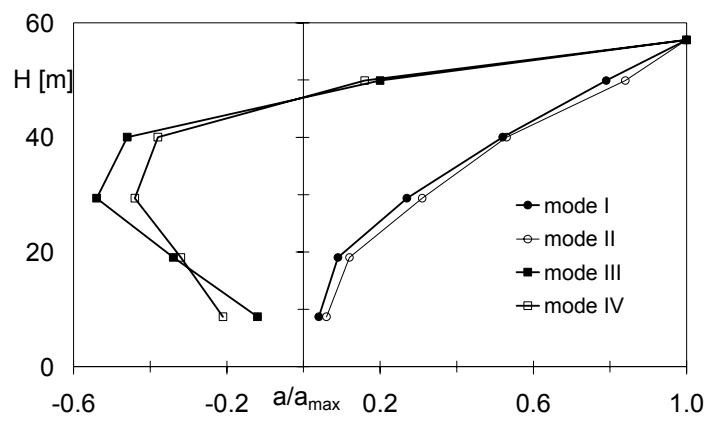

Figure 3: $\quad$ Experimental normalized modal shapes.

\section{The FEM model}

Based on the detailed geometrical relief of the Bell Tower, a 3D finite element modelling of the structure has been performed with the commercial software DIANA TNO (release 8.1). Brick elements (HX24L, DIANA [4]) have been used for the first $57 \mathrm{~m}$ until the level where the pear dome starts. Thickness of masonry walls has been modelled using several three-dimensional blocks having height variable between $0.5 \mathrm{~m}$ and $1.5 \mathrm{~m}$, width and thickness of about $0.5 \mathrm{~m}$ : this geometry allowed to model with good accuracy the variability of walls thickness along the height of the tower and to introduce the openings. The pear dome has been modelled by shell elements (Q20SH, DIANA [4]). Floors have been modelled following the geometrical shape of vaults and slabs, while RC stairs have been not considered in the model.

Respect to the experimental values of density obtained by stone samples, the lower values of $12 \mathrm{kN} / \mathrm{m}^{3}$ until the first floor (about $+9 \mathrm{~m}$ ) and $11 \mathrm{kN} / \mathrm{m}^{3}$ for the higher levels are assumed for the tuff and $16 \mathrm{kN} / \mathrm{m}^{3}$ for the clay bricks. These lower values have been established to take into account the presence of voids, mortar, filling material in the masonry assembly, especially for the faced tuff 
masonry. Density of tuff is considered a little higher for the lower levels to take into account the piperno covering of the basement. Compressive strength of masonry assembly is assumed equal to $1.4 \mathrm{MPa}$ for tuff and $2.4 \mathrm{MPa}$ for claybricks according to the results of double flat-jacks. For the tensile strength, lacking of any experimental reference, the $5 \%$ of the compressive strength (Augenti [5]) is considered (0.07MPa for tuff, $0.12 \mathrm{MPa}$ for clay bricks).

For the linear elastic branch of the constitutive law, the same elastic modulus is used for compressive and tensile loading, adopting an isotropic behaviour with a Poisson modulus of 0.15 . The experimental values of elastic modulus (530 and $850 \mathrm{MPa}$ for tuff and clay bricks) have been increased in the modelling of about $50 \%$ to simulate a global stiffening effect due to stone covering, RC stairs, reinforced mortar injections, steel chains, presence of heavy decorative elements at the higher and slender levels. Furthermore the values have been assessed also by performing a parametric analysis by comparing the experimental and theoretical dynamic behaviour of the structure.

A post peak behavior with softening and damage is considered both for compression and tension. For the tension behaviour a smeared crack damage model type Hordijk has been assumed and, after reaching the tensile strength, the post-peak behaviour is modelled by a linear softening branch until a maximum value of strain ( 0.0004 for tuff and 0.00055 for clay bricks) calculated by the fracture energy value, fixed on the basis of literature data for analogous masonries $(1.65 \mathrm{~N} / \mathrm{m}$ for tuff and $3.65 \mathrm{~N} / \mathrm{m}$ for clay bricks). Furthermore the compressive behaviour after the peak is modelled firstly by a linear softening branch until a fixed strain (0.004 for tuff and 0.005 for clay bricks), after that stresses assume a constant residual value (30\% of strength) for indefinite strain.

\subsection{Linear analysis for gravity loads}

Firstly a linear analysis of the structure under vertical loads has been performed by DIANA according two configurations: one considering ineffective the actions of all surrounding structures (configuration A), so that the Tower is completely bind only at the basement; the other (configuration B) taking into account the effect of the adjacent buildings by horizontal supports in $\mathrm{x}$ direction for the sides confining with the church and the congregation building and in $y$ direction for the side confining with the convent/cloister for the first $19 \mathrm{~m}$, corresponding to the last level constrained by the surrounding buildings.

The experimental stresses measured in situ are compared in Table 1 with the theoretical ones given by the FEM model in both configurations. Generally the theoretical values are lower in the configuration B and overestimate the experimental values at the downer levels with errors variable between $10 \%$ and $30 \%$, while are very similar at the higher levels made by clay bricks.

In Figure 4 the stress distribution along the entire Tower is reported (compressive stresses are assumed negative) for configuration $\mathrm{B}$, evidencing that higher stresses are localized at the lower level $(0.68 \mathrm{MPa}$ at the ground level) with a mean value of $0.5 \mathrm{MPa}$. Furthermore at the higher levels, where section shape becomes octagonal and walls are made by clay bricks, the stresses are lower and meanly about $0.15 \mathrm{MPa}$. This was predictable considering that the 
higher part of the Tower has several openings respect to the basement that is more massive. Elevate stresses are registered at the corners along the perimeter of the plants or near the openings where high concentration can develop.

Table 1: Experimental and theoretical stresses.

\begin{tabular}{|c|c|c|c|c|}
\hline \multirow{3}{*}{$\begin{array}{l}\text { Flat } \\
\text { jack }\end{array}$} & \multirow{3}{*}{$\begin{array}{c}\text { Level } \\
{[\mathrm{m}]}\end{array}$} & \multicolumn{3}{|c|}{ Stresses [MPa] } \\
\hline & & \multirow{2}{*}{ Exp. } & \multicolumn{2}{|c|}{ Theoretical } \\
\hline & & & (A) & (B) \\
\hline MS1 & 8.7 & 0.35 & 0.45 & 0.33 \\
\hline MS2 & 8.7 & 0.30 & 0.42 & 0.33 \\
\hline MS3 & 0.0 & 0.35 & 0.55 & 0.46 \\
\hline MS4 & 19.0 & 0.26 & 0.40 & 0.35 \\
\hline MS5 & 19.0 & 0.26 & 0.30 & 0.31 \\
\hline MS6 & 40.0 & 0.17 & 0.15 & 0.19 \\
\hline MS7 & 40.0 & 0.17 & 0.20 & 0.21 \\
\hline
\end{tabular}
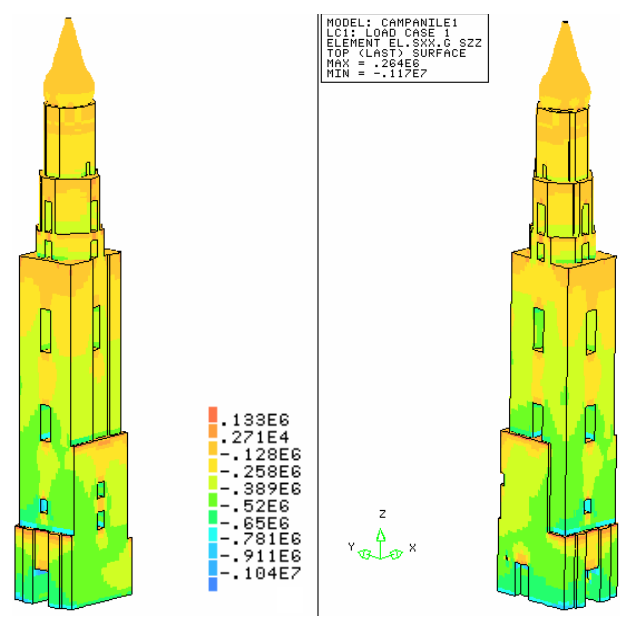

Figure 4: $\quad$ Principal stress along the Tower (in N/m $\mathrm{m}^{2}=10^{6} \mathrm{MPa}$ ).

The stress map at various levels evidences a light stress increase along the bisector line of X-Y plane in the versus of the Tower front side, that gradually dampens at higher levels: this trend is probably due to the effect of a light geometrical eccentricity of the structure, progressively reducing toward the top. In conclusion with exception of some particular points the maximum stresses are in the range of $35 \%$ of the strength for the tuff and of $6-7 \%$ for the clay brick and, despite the eccentricity effects, no tension stress appears in the distribution.

\subsection{Linear dynamic analysis}

A dynamic modal analysis of the Tower has been developed by the 3D FEM previously introduced assuming a linear elastic behaviour for all materials. 
Various boundary configurations have been considered to evaluate the effect of adjacent buildings on the dynamic response of the structure. In addition to the configurations $\mathrm{A}$ and $\mathrm{B}$, already modelled in the linear static analysis, other two configurations, taking into account the effects of lateral buildings, have been considered in order to assess the boundary conditions giving the best agreement with the experimental results. Firstly (configuration $\mathrm{C}$ ), the effects of lateral buildings are modelled by elastic restrains (springs), in the hypothesis that the interaction depends on the deformability properties of adjacent elements. Then (configuration D), parts of lateral buildings confining with the Tower are partially $3 \mathrm{D}$ modelled. A parametric analysis varying the value of elastic modulus of materials has been also developed in parallel with the evaluation of the restrain effect. In Table 2 frequencies (f) and periods (T) of the first five vibration modes are reported for the described boundary conditions, evidencing that the period increases when configuration is more deformable.

Table 2: $\quad$ Dynamic characterization of Tower in elastic linear behaviour.

\begin{tabular}{|c|c|c|c|c|c|c|c|}
\hline \multirow{2}{*}{ Mode } & \multirow{2}{*}{ Tipology } & \multirow{2}{*}{ Experimental results } & \multicolumn{4}{|c|}{ Numerical FEM Analysis by DIANA } \\
\cline { 3 - 8 } & & & $\mathrm{f})$ & $(\mathrm{B})$ & $(\mathrm{C})$ & $(\mathrm{D})$ \\
\hline & & $\mathrm{f}[\mathrm{hz}]$ & $\mathrm{T}[\mathrm{hz}]$ & $\mathrm{f}[\mathrm{hz}]$ & $\mathrm{f}[\mathrm{hz}]$ & $\mathrm{f}[\mathrm{hz}]$ & $\mathrm{f}[\mathrm{hz}]$ \\
\hline 1 & Flex x & $\mathbf{0 . 6 9}$ & 1.45 & 0.47 & 0.69 & 0.66 & 0.62 \\
\hline 2 & Flex y & $\mathbf{0 . 7 6}$ & 1.32 & 0.56 & 0.77 & 0.74 & 0.67 \\
\hline 3 & Flex x & $\mathbf{2 . 2 8}$ & 0.44 & 1.88 & 2.60 & 2.43 & 2.31 \\
\hline 4 & Flex y & $\mathbf{2 . 3 5}$ & 0.43 & 2.11 & 2.75 & 2.61 & 2.42 \\
\hline 5 & Torsional & $\mathbf{2 . 7 6}$ & 0.36 & 2.85 & 3.54 & 3.33 & 2.97 \\
\hline
\end{tabular}

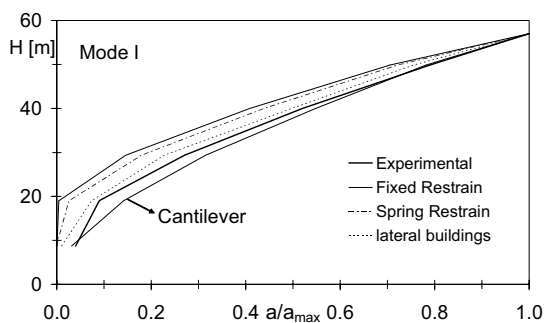

(a)

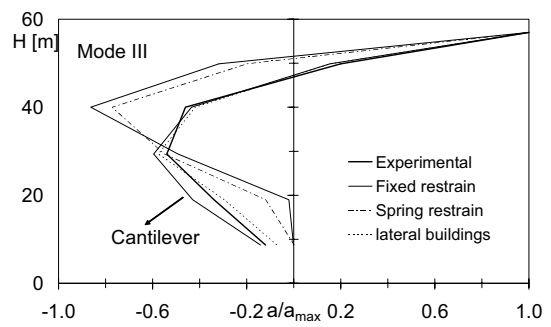

(c)

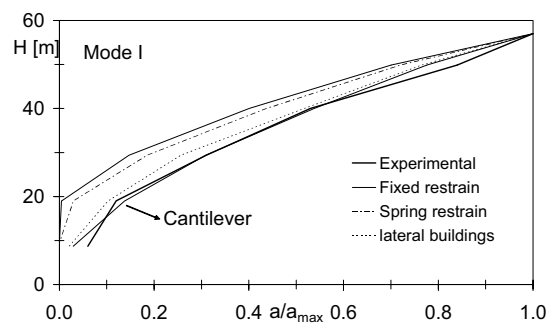

(b)

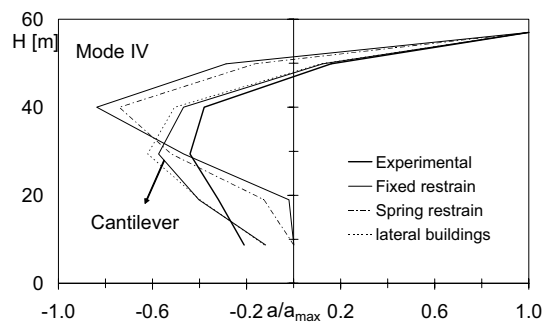

(d)

Figure 5: $\quad$ Normalized modal shapes: (a) Mode I; (b) Mode II; (c) Mode III; (d) Mode IV. 
In Figures 5 the normalized theoretical and experimental modal shapes corresponding to the first four vibration modes are reported for all the examined configurations. The comparisons between experimental and numerical results show that in terms of natural frequencies the behaviour of the Tower is proximal to the configuration with fixed restrains (B), while the experimental modal shapes are very similar to the cantilever configuration (A). Configuration D seems to give the best agreement between numerical and experimental results both in terms of frequencies and modal shapes. In conclusion the experimental modal shapes evidence a negligible effects of the lateral buildings (more significant in $\mathrm{X}$ direction respect to $\mathrm{Y}$ direction where only some floors of the cloister could have a restraining effect), while the values of frequencies lead to hypothesize a stiffer behaviour respect to the cantilever scheme, for the low dynamic action produced by the environmental sources. When a strong dynamic action occurs, as an earthquake, probably the effectiveness of these kinds of restrains is reduced and the Tower behaves like an isolated element. Furthermore this is also confirmed by various inquires that lead to suppose that the Tower was originally built separately from the other buildings, particularly from the Church, and that was surrounded successively.

\subsection{Push-over analysis}

A nonlinear static analysis has been developed by the 3D FEM to define the behaviour of the Bell Tower under seismic actions. Two load distributions, analogous to the first and second modal shape related to configuration $\mathrm{A}$ (cantilever scheme), have been applied horizontally to the structure separately along directions $\mathrm{X}$ and $\mathrm{Y}$ in order to plan a Push-Over analysis (Magenes [6]). The nonlinear behaviour of the structure under horizontal actions can be expressed by the capacity displacement curve, i.e. the relation between the resultant action of the applied forces (maximum shear at the basement or acceleration expressed in $\mathrm{g}$ obtained by dividing the force to the mass of the structure) and the displacement of a control point of the structure In Figure 6 the capacity displacement curves, referring to the displacement at the top of the cover dome $(+67.6 \mathrm{~m})$, are reported for both directions and versus.

For each direction the analysis has been stopped at the shear value corresponding to the collapse of the structure due to the presso-flexure crisis of the base section. Diffuse tensile stresses result at level of $41.4 \mathrm{~m}$ and where the section has a setback becoming octagonal. At the basement, both compressive and tensile stresses overcome the relative peak strength, so that in a relevant part of the section the materials have a nonlinear behaviour. The distributions of tensile stresses show that for the levels made by clay bricks the tensile stresses do not surmount the corresponding strength, while for the levels made by tuff until about $34 \mathrm{~m}$, the tensile stresses overcome the peak strength so that the tensile behaviour attains the post peak softening range.

The capacity displacement curves summarize the global behaviour of the structure and is used to assimilate the behaviour of the real structure, that is a complex system with more degrees of freedom (DOF), to the nonlinear behaviour of a simple equivalent oscillator (1-DOF system). The maximum 


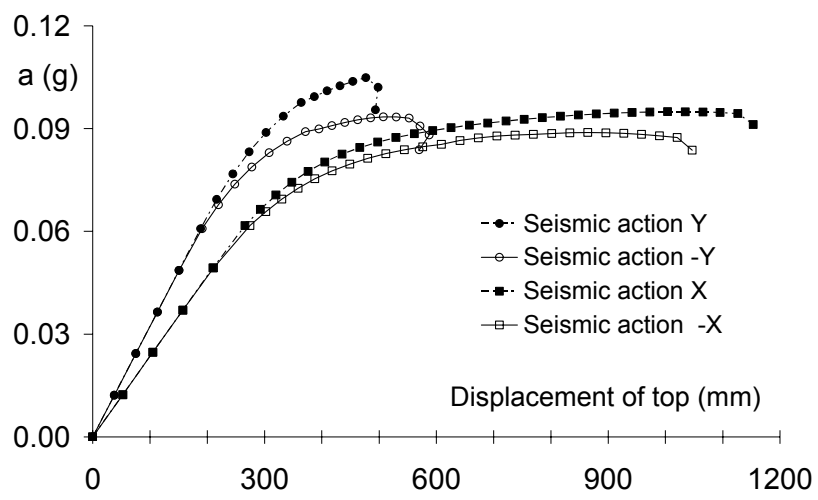

Figure 6: Capacity displacement curve of the Tower.

displacement capacity of the 1-DOF system has to be compared with the maximum displacement requested (displacement demand, $\mathrm{d}_{\mathrm{m}}{ }_{\mathrm{m}}$ ) calculated basing on the Italian seismic code (OCPM 3431 [7]).

For the examined site, the maximum acceleration at bedrock having a happening probability of $10 \%$ in 50 years (PGA) is $0.168 \mathrm{~g}$ (Calvi and Stucchi [8]) and the worst typology of foundation soil is assumed basing on the geotechnical properties of the site. Using these values, the displacement demand for the equivalent 1 -DOF system is $226 \mathrm{~mm}$ that multiplied for the coefficient $\Gamma=1.71$, corresponds to a requested displacement of $386 \mathrm{~mm}$ for the real structure. Compared to this demand, the structure shows for both the directions a sufficient displacement capacity with safety factors of 2.24, 1.52 and 1.24 respectively for $-\mathrm{X},+\mathrm{Y}$ and $-\mathrm{Y}$ direction, meaning that the Tower is able to sustain the design seismic action, if the nonlinear behaviour is assumed.

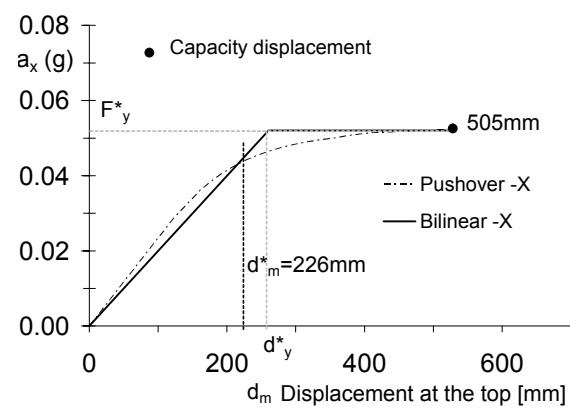

(a)

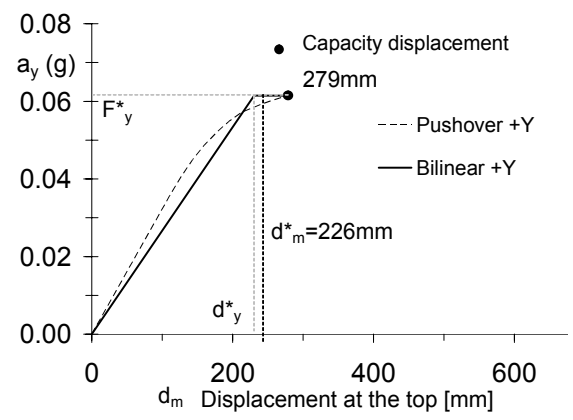

(b)

Figure 7: $\quad$ Capacity displacement curve of 1-dof system: (a) $-\mathrm{X}$; (b) + Y . 
In Figure 7 the capacity displacement curves of the 1-DOF equivalent system are reported for each direction having the lowest safety factors ( $\mathrm{X}$ and $+\mathrm{Y})$.

All the numerical analyses have been developed assuming that walls are well connected in the corners: this means that no local cinematic mechanism out of the plane is supposed activated. Qualitative indications about the reliability that out-of-plane phenomena develop are evidenced by the presence of several steel chains and reinforced injections realized in the past, probably just to improve the global monolithic behaviour. To this aim a detailed analysis of the existing steel chains was performed to evaluate their efficiency into avoid eventual out-ofplane mechanisms. Assuming the very conservative hypothesis that walls are laterally connected each other and that the floors give no restraining effect at the top and the bottom, the masonry panels behave as single blocks susceptible to collapse out of the plane for the effect of horizontal loads. If this type of verify is not satisfied, new connective systems have to be designed in substitution or in addition of the existing ones to increase the 'box' behaviour of the building.

\section{Conclusions and future outcomes}

For the Bell Tower of Santa Maria of Carmine a multidisciplinary approach has been applied in order to develop a reliable model of the structural behaviour under vertical loads and seismic actions. The detailed state-of-art through historical inquires, geometrical and material relieves, experimental tests in situ have pointed out material heterogeneities, irregularity of shapes, dimensions and restrains conditions, presence of interventions realized in the past that make complex the assessment of the structural behaviour.

Experimental results of tests in situ and the linear static analysis performed by 3D FE model evidenced that the Tower is low stressed for the vertical loads. The same 3D model has been well assessed basing on the experimental dynamic behaviour of the Tower defining the restrain configurations and the elastic modulus of materials. Then, a nonlinear static analysis (Push Over) has been developed evidencing that the structure is able to sustain the seismic action expected in situ. This safe condition has been defined by introducing a nonlinear behaviour of the structure through a nonlinear constitutive relationship of masonry.

Furthermore studies about the effectiveness of connections between walls are in progress to evaluate the possibility of out-of-plane local failure mechanisms and evaluate the necessity of improving the global behaviour of the Tower by new connective systems.

\section{Acknowledgements}

Activities on the Bell Tower of Santa Maria del Carmine have been developed in the within of the project PON TEMPES with the collaboration of the architectural heritage authority of Campania. 


\section{References}

[1] Binda L, Saisi A, Tiraboschi C., Investigation procedures for the diagnosis of historic masonries. Construction and Building Materials 2000;14:199233.

[2] Carpinteri A, Bocca P., Damage and diagnosis of materials and structures. Proc. of DDMS 91. Politecnico di Torino, Bologna: Pitagora; 1991.

[3] Ceroni F., Pecce M., Voto S., Historical, architectonic and structural investigations of the Bell Tower of Santa Maria del Carmine, XXXIV IAHS world congress sustainable house design, Napoli, Settembre 2006.

[4] DIANA finite elements analysis, User's manual - Release 8.1 - Element Library, Material Library, TNO Building and Construction Research, Department of computational Mechanics, A.A. Delft, the Netherlands, 2002.

[5] Augenti N., Il calcolo sismico degli edifici in muratura, UTET Libreria Srl, 2000 (in italian).

[6] Magenes, G., A method for pushover analysis in seismic assessment of masonry buildings, 12th World Conference on Earthquake Engineering, Auckland, New Zealand, January 30-February 4, 2000 (CD-ROM).

[7] OCPM 3431, Ordinanza del Presidente del Consiglio dei ministri (2005) Primi elementi in materia di criteri generali per la classificazione sismica del territorio nazionale e di normative tecniche per le costruzioni in zona sismica, Document no.3431 (in Italian).

[8] Calvi G.M., Stucchi M., 2006, http://esse1.mi.ingv.it/pga.html, INGV, Istituto Nazionale di Geofisica e Vulcanologia, seismic risk map provided by OPCM 3274. 